\title{
NO donor and MEK inhibitor synergistically inhibit proliferation and invasion of cancer cells
}

\author{
SATOSHI FURUHASHI ${ }^{1}$, HIROKI SUGITA ${ }^{1,2}$, HIROSHI TAKAMORI ${ }^{1}$, KEI HORINO ${ }^{1}$, OSAMU NAKAHARA ${ }^{1}$, \\ HIROHISA OKABE ${ }^{1}$, KEISUKE MIYAKE $^{1}$, HIROSHI TANAKA ${ }^{1}$, TORU BEPPU ${ }^{1}$ and HIDEO BABA ${ }^{1}$ \\ ${ }^{1}$ Department of Gastroenterological Surgery, Graduate School of Medical Sciences, \\ Kumamoto University, 1-1-1 Honjo, Kumamoto 860-8556; ${ }^{2}$ Department of Surgery, \\ Kumamoto City Municipal Hospital, 1-1-60 Koto, Kumamoto 862-8505, Japan
}

Received August 27, 2011; Accepted October 3, 2011

DOI: $10.3892 /$ ijo.2011.1243

\begin{abstract}
Nitric oxide (NO) shows tumoricidal activity. We had previously reported that NO downregulates the phosphatidylinositol-3-kinase/Akt pathway, but upregulates the MEK/ERK pathway downstream of growth factor signaling. We hypothesized that NO donor and MEK inhibitor in combination synergistically inhibit the viability of cancer cells compared to either NO donor or MEK inhibitor alone. We determined the effects of S-nitrosoglutathione (GSNO, NO-donor) and U0126 (MEK inhibitor) on insulin-like growth factor-I (IGF-I) and epidermal growth factor (EGF) signaling, proliferation and invasion in cancer cell lines. GSNO inhibits phosphorylation of IGF-I receptor (IGF-IR), EGF receptor (EGFR) and Akt, but upregulates ERK1/2 phosphorylation in MIAPaCa-2 and HCT-116 cells after stimulation by IGF-I and EGF. On the other hand, U0126 inhibits phosphorylation of ERK1/2, but upregulates phosphorylation of IGF-IR and EGFR in MIAPaCa-2 and HCT-116 cells. The combination of GSNO and U0126 downregulates phosphorylation of IGF-IR, EGFR, Akt and ERK1/2 after stimulation by IGF-I and EGF. GSNO as well as U0126, inhibits the proliferation of MIAPaCa-2, HCT-116, Panc-1, MCF-7, HT-29 and AGS cells in a dose-dependent manner. GSNO and U0126 in combination synergistically inhibit proliferation and invasion of cancer
\end{abstract}

Correspondence to: Dr Hiroki Sugita or Dr Hideo Baba, Department of Gastroenterological Surgery, Graduate School of Medical Sciences, Kumamoto University, 1-1-1 Honjo, Kumamoto 860-8556, Japan

E-mail: sugitaf@ba2.so-net.ne.jp

E-mail: hdobaba@kumamoto-u.ac.jp

Abbreviations: IGF-IR, IGF-I receptor; EGF, epidermal growth factor; EGFR, EGF receptor; NO, nitric-oxide; IRS-1, insulin receptor substrate-1; PI3K, phosphatidylinositol-3-kinase; GSNO, S-nitrosoglutathione; ERK, extracellular signal-regulated kinase; PTC, papillary thyroid carcinoma

Key words: nitric oxide, MEK, insulin-like growth factor receptor, epidermal growth factor receptor, Akt, extracellular signal-regulated kinase, cancer proliferation, cancer invasion, pancreatic cancer, colon cancer cells. These results indicate that the combined treatment of NO donor and MEK inhibitor may be promising in cancer therapy.

\section{Introduction}

Insulin-like growth factor (IGF) and epidermal growth factor (EGF) signaling play a key role in cancer proliferation and invasion (1-5). IGF-I and EGF bind to IGF-I receptor and EGF receptor and then phosphorylate the tyrosine of the cognate receptors. Insulin receptor substrate (IRS)-1, an adaptor protein, exists mainly in the cytosol, and binds to phosphorylated IGF-IR, resulting in phosphorylation and activation of IRS-1. IRS-1 and EGF receptor (EGFR) transduce phosphatidylinositol-3-kinase (PI3K), which in turn activates further downstream components, including Akt. Alternatively, phosphorylated and activated EGFR and IRS-1 can also bind to another adaptor protein, Grb-2, which activates the MEK/ ERK pathway, another major IGF and EGF signaling cascade parallel to the PI3K/Akt pathway $(6,7)$.

Recent studies have shown that nitric-oxide (NO) plays a role in the posttranslational modification of proteins (8-11). Controversial results have been reported regarding the roles of NO in cancer. Recent papers reported that endogenous NO promotes oncogenesis and angiogenesis in various cancers $(12,13)$. In contrast, other studies have shown that NO inhibits cell proliferation and induces apoptosis in various cells including cancer cells, in vitro and in vivo (14-21). These studies suggest that $\mathrm{NO}$ can act either as a tumor suppressor or as a tumor enhancer depending on cell type and the level of NO in the cells. However, the molecular mechanism underlying the inhibitory effects of NO on cancer viability, remains unclear. We have reported that $\mathrm{NO}$ inhibits cancer cell proliferation and invasion through downregulation of IRS-1 protein, resulting in inhibition of the PI3K/Akt pathway (14). In contrast, $\mathrm{NO}$ enhances nitrosylation and activates N-Ras and H-Ras proteins (22). Members of the Ras family of small GTPase proteins including K-Ras, N-Ras, and H-Ras, play central roles in the transduction of growth factor signals (23). Thus, NO downregulates the PI3K/Akt pathway, but upregulates the MEK/ERK pathway. Therefore, we hypothesized that the combination of NO donor and MEK inhibitor synergistically inhibits the proliferation and invasion of cancer cells 
compared to either NO donor or MEK inhibitor alone. In the present study, we demonstrated that combination treatment of NO donor and MEK inhibitor shows greater inhibitory effects on the proliferation and invasion of cancer cells compared to either MEK inhibitor or NO donor alone, which are associated with the inhibition of both the PI3K/Akt and MEK/ERK pathways. These data provide new insight into the molecular basis underlying the regulation of cancer viability.

\section{Materials and methods}

Materials. S-nitrosoglutathione (GSNO) and U0126 were purchased from Calbiochem (San Diego, CA). Recombinant IGF-I and EGF were purchased from Peprotech (London, UK). Antibodies against phospho-Tyr 1135/1136 IGF-I R $\beta$, phosphoTyr1068EGFR, phospho-Ser 473 Akt, phospho-ERK1/2, IGF-IR, EGFR, Akt, and ERK1/2 were purchased from Cell Signaling Technology (Beverly, MA).

Cell culture. MIAPaCa-2, HCT-116, Panc-1, MCF-7, HT-29 and AGS cells were obtained from the American Type Culture Collection (Manassas, VA), and were maintained in Dulbecco's modified Eagle's medium (DMEM) and RPMI-1640 medium supplemented with $10 \%$ fetal bovine serum (FBS) at $37^{\circ} \mathrm{C}$ in a humidified atmosphere of $5 \% \mathrm{CO}_{2}$.

Cell lysis. Cells were lysed with cell lysis buffer [50 mM Tris- $\mathrm{HCl}$ (pH 7.6), $150 \mathrm{mM} \mathrm{NaCl}, 10 \mathrm{mM}$ sodium fluoride, $2 \mathrm{mM}$ sodium vanadate, $1 \mathrm{mM}$ PMSF, $10 \mu \mathrm{g} / \mathrm{ml}$ aprotinin, $10 \mu \mathrm{g} / \mathrm{ml}$ leupeptin, $1 \mathrm{mM}$ DTT, and 1\% NP-40]. Following incubation on ice for $30 \mathrm{~min}$, lysate samples were centrifuged at $13,000 \mathrm{~g}$ for $30 \mathrm{~min}$. Aliquots of the supernatant containing equal amounts of protein, determined using Lowry assay, were subjected to immunoblotting followed by sodium dodecyl sulfate-polyacrylamide gel electrophoresis (SDS-PAGE).

Immunoblotting. A total of $20 \mu \mathrm{g}$ of each protein sample was mixed with $5 \mathrm{X}$ sample buffer including $10 \% \beta$-mercaptoethanol and the mixture was boiled for $5 \mathrm{~min}$. The total cellular protein extracts were separated on $10 \%$ SDS polyacrylamide gels. The extracts were electrophoretically transferred onto nitrocellulose membranes (Bio-Rad, Hercules, CA), the membranes were blocked with $5 \%$ nonfat dried milk for $2 \mathrm{~h}$ at room temperature, and incubated with primary antibody for either $2 \mathrm{~h}$ at room temperature or overnight at $4^{\circ} \mathrm{C}$. This was followed by incubation with secondary antibody conjugated with antirabbit or mouse IgG antibody peroxidase for $2 \mathrm{~h}$ at room temperature. Detection was done with an enhanced chemiluminescence (ECL) reagent (GE Healthcare, Piscataway, NJ). Bands of interest were scanned by using Colorio GT-X970 (Epson, Tokyo, Japan) and were quantified with NIH Image 1.62 software (NTIS, Springfield, VA).

Cell proliferation assay. The mixture of GSNO (NO donor), U0126 (MEK inhibitor) and $100 \mu \mathrm{l}$ of medium containing $5 \times 10^{3}$ cancer cells was added to each well (of a 96-well plate). Cell proliferation assay was performed using Cell Counting kit-8 containing 2-(2-methoxy-4-nitrophenyl)-3-(4-nitrophenyl)5-(2,4-disulfophenyl)-2H-tetrazolium (WST-8) (Dojin Laboratories, Kumamoto, Japan) after the incubation for $72 \mathrm{~h}$.
At the end of each experiment, the cell proliferation reagent WST-8 was added to each well and the plates were incubated at $37^{\circ} \mathrm{C}$ for $2 \mathrm{~h}$. Optical density (OD) (A450 nm) was measured using an automatic microplate reader (Molecular Devices, Sunnyvale, CA). Each experiment was performed in triplicate.

Invasion assay. The invasive activities of cultured MIAPaCa-2 and HCT-116 cells were assayed using BD BioCoat Matrigel invasion chambers (BD Biosciences, Bedford, MA). MIAPaCa-2 cells were initially seeded on a 24 -well plate at a density of $5 \times 10^{4}$ cells/well and cultured in DMEM/10\% FBS, in the presence of $1 \%$ glutamine and antibiotics $(1 \%$ penicillin and streptomycin sulfate) at $37^{\circ} \mathrm{C}$ in a humidified atmosphere of $5 \% \mathrm{CO}_{2}$. Medium containing NIH3T3 fibroblasts in the lower chamber served as a chemoattractant. The cells were then exposed to NO donor (GSNO $200 \mu \mathrm{M}$ ) and MEK inhibitor (U0126 $10 \mu \mathrm{M}$ ). The chambers were incubated for $24 \mathrm{~h}$, to determine invasion efficiency. HCT-116 cells were initially seeded on a 24-well plate at a density of $1 \times 10^{5}$ cells/well and cultured in RPMI-1640/10\% FBS, in the presence of $1 \%$ glutamine and antibiotics (1\% penicillin and streptomycin sulfate) at $37^{\circ} \mathrm{C}$ in a humidified atmosphere of $5 \% \mathrm{CO}_{2}$. Medium containing NIH3T3 fibroblasts in the lower chamber served as a chemoattractant. The cells were then exposed to NO donor (GSNO $200 \mu \mathrm{M}$ ) and MEK inhibitor (U0126 $10 \mu \mathrm{M}$ ). The chambers were incubated for $48 \mathrm{~h}$, to determine invasion efficiency. MIAPaCa-2 and HCT-116 cells on the upper surface of the filter were removed using a cotton-wool swab, and the cells that had invaded the lower surface were stained with $1 \%$ toluidine blue after fixation in $100 \%$ methanol. The number of invading cells was counted in 5 randomly selected fields under a light microscope. Each experiment was performed in triplicate.

Statistical analysis. Statistical analysis was performed using the StatView J-5.0 program (Abacus Concepts Inc., Berkeley, CA). Comparisons were carried out using Student's t-test, and $\mathrm{P}<0.05$ were considered statistically significant. ANOVA followed by Tukey-Kramer post hoc test was used to compare multiple samples, with a significance level of 0.05 .

\section{Results}

NO donor and MEK inhibitor influence IGF-I signaling in MIAPaCa-2 cells. Stimulation of IGF-I resulted in marked phosphorylation of IGF-IR, Akt and ERK1/2 in MIAPaCa-2 cells. GSNO, a NO donor, inhibited IGF-I-stimulated phosphorylation of IGF-IR and Akt. On the other hand, GSNO induced phosphorylation of ERK1/2 without stimulation of IGF-I, and enhanced IGF-1-stimulated phosphorylation of ERK1/2. However, GSNO did not influence IGF-IR, Akt, and ERK1/2 protein expression in MIAPaCa-2 cells. U0126, a MEK inhibitor, inhibited IGF-I-stimulated phosphorylation of ERK1/2. On the other hand, surprisingly, U0126 enhanced IGF-I-stimulated tyrosine phosphorylation of IGF-IR, without the influence of IGF-IR protein expression. In addition, U0126 upregulates IGF-I-stimulated phosphorylation of Akt. The combination of GSNO and MEK inhibitor inhibited IGF-I-stimulated phosphorylation of IGF-IR, Akt, and ERK1/2 without the influence of IGF-IR, Akt, and ERK1/2 protein expression (Fig. 1). 

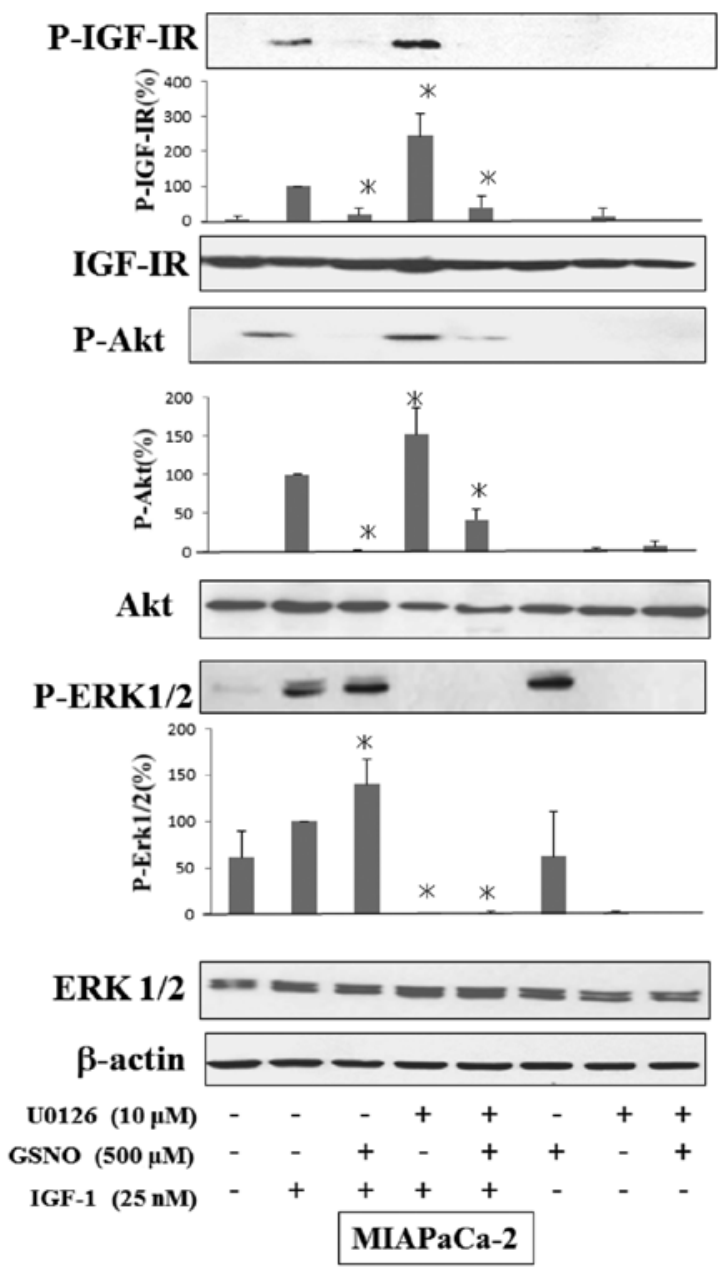

Figure 1. Regulation of insulin-like growth factor (IGF) signaling by nitric oxide (NO) donor and MEK inhibitor in MIAPaCa-2 cells. MIAPaCa-2 cells were incubated in DMEM with 10\% FBS overnight and grown to $80 \%$ confluency. The cells were then incubated with S-nitrosoglutathione (GSNO) $(500 \mu \mathrm{M})$ and $\mathrm{U} 0126(10 \mu \mathrm{M})$ for $6 \mathrm{~h}$. After the starvation of serum for $2 \mathrm{~h}$, the cells were incubated with IGF-I $(25 \mathrm{nM})$ for $5 \mathrm{~min}$ and then harvested. Cell lysates were subjected to immunoblotting (IB). All experiments were repeated three times and similar results were obtained. Bands of interest were scanned by using Colorio GT-X970 and were quantified by using NIH Image 1.62 software. The results of densitrometry analysis of each band were compared to control, which was the band of IGF-I-stimulated p-Akt, p-ERK1/2, and p-IGF-IR without the administration of either GSNO or U0126. Error bars indicate the standard errors of the means. " $\mathrm{P}<0.05$ compared to control.

$N O$ donor and MEK inhibitor influence EGF signaling in HCT-116 cells. Stimulation of EGF resulted in marked tyrosine phosphorylation of EGFR, Akt and ERK1/2 in HCT-116 cells. GSNO inhibited EGF-stimulated phosphorylation of EGFR and Akt. However, GSNO induced phosphorylation of ERK1/2 without stimulation of EGF, and enhanced EGF-stimulated phosphorylation of ERK1/2. U0126 inhibited EGF-stimulated phosphorylation of ERK1/2. On the other hand, surprisingly, U0126 enhanced EGF-stimulated tyrosine phosphorylation of EGFR without the influence of EGFR protein expression. In addition, U0126 upregulates EGF-stimulated phosphorylation of Akt. The combination of GSNO and U0126 inhibited EGF-stimulated phosphorylation of EGFR, Akt and ERK1/2 without the influence of EGFR, Akt, and ERK1/2 protein expression (Fig. 2).
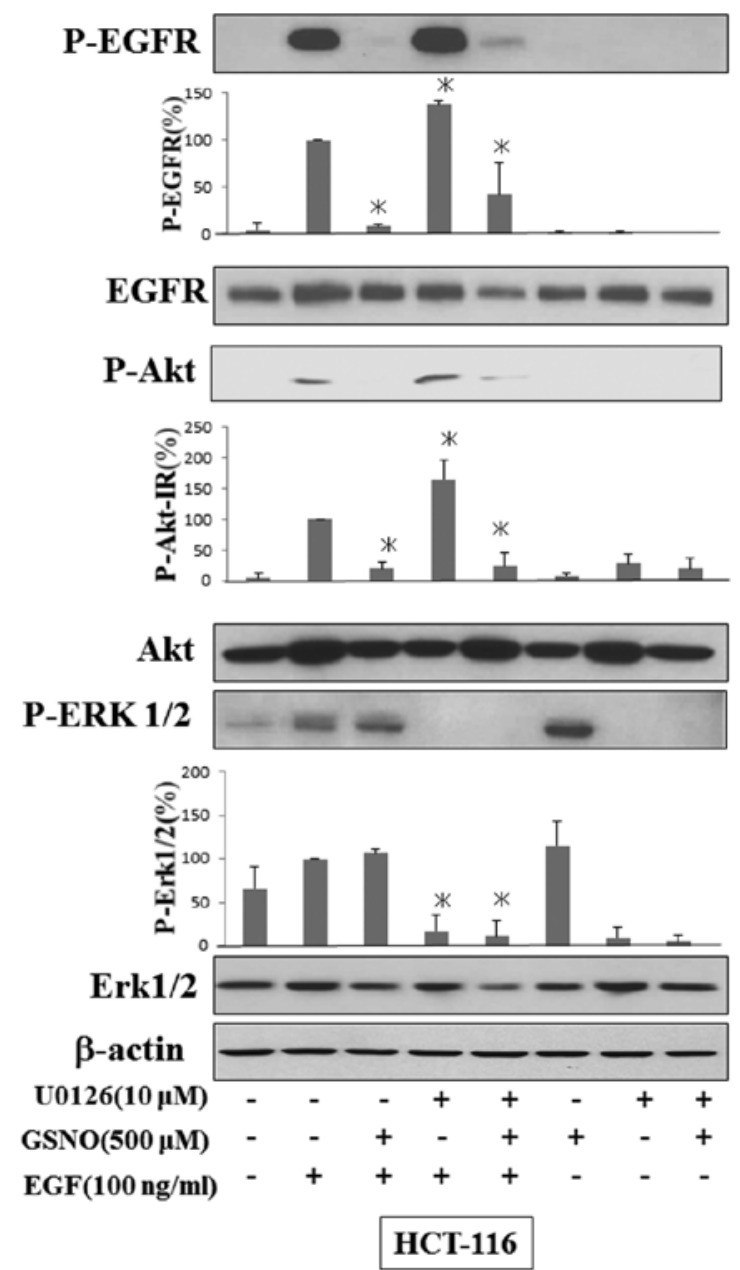

Figure 2. Regulation of EGF signaling by NO donor and MEK inhibitor in HCT-116 cells. HCT-116 cells were incubated in RPMI-1640 with 10\% FBS overnight and grown to $80 \%$ confluency. The cells were then incubated with GSNO $(500 \mu \mathrm{M})$ and $\mathrm{U} 0126(10 \mu \mathrm{M})$ for $6 \mathrm{~h}$. After the starvation of serum for $2 \mathrm{~h}$, the cells were incubated with EGF $(100 \mathrm{ng} / \mathrm{ml})$ for $5 \mathrm{~min}$ and then harvested. Cell lysates were subjected to immunoblotting. All experiments were repeated three times and similar results were obtained. Bands of interest were scanned by using Colorio GT-X970 and were quantified with NIH Image 1.62 software. The results of densitrometry analysis of each band were compared to control, which was the band of EGF-stimulated p-Akt, p-ERK1/2, and p-IGF-IR without the administration of either GSNO or U0126. Error bars indicate the standard errors of the means. ${ }^{*} \mathrm{P}<0.05$, compared to control.

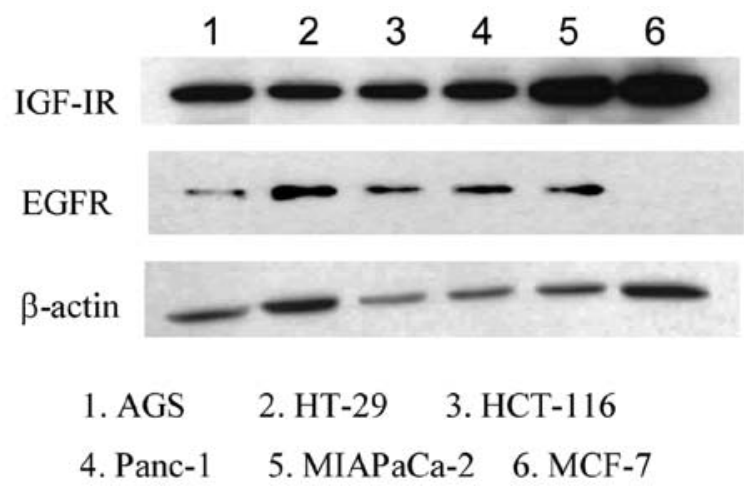

Figure 3. IGF-IR and EGFR protein expression in cancer cells. Cell lysates of MIAPaCa-2 cells, HCT-116, Panc-1, MCF-7, HT-29 and AGS cells were subjected to immunoblotting and then IGF-IR and EGFR protein was detected. 

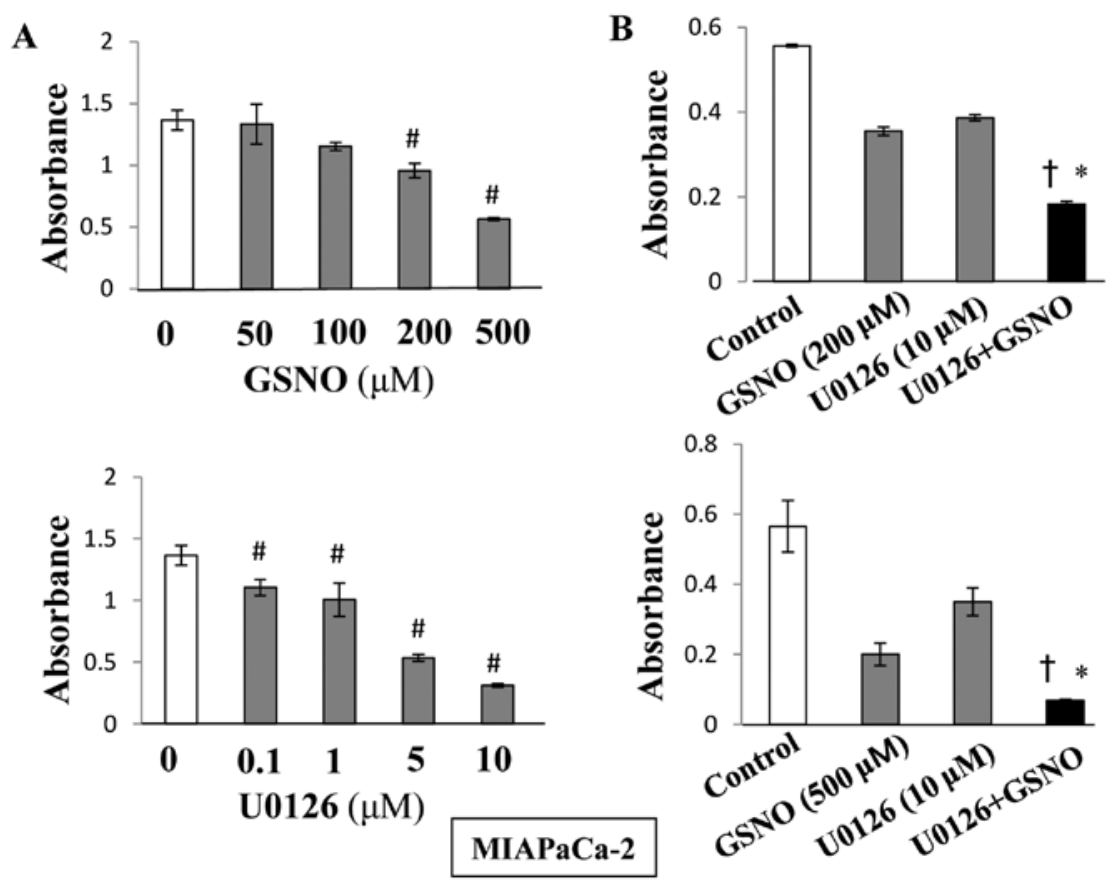

C
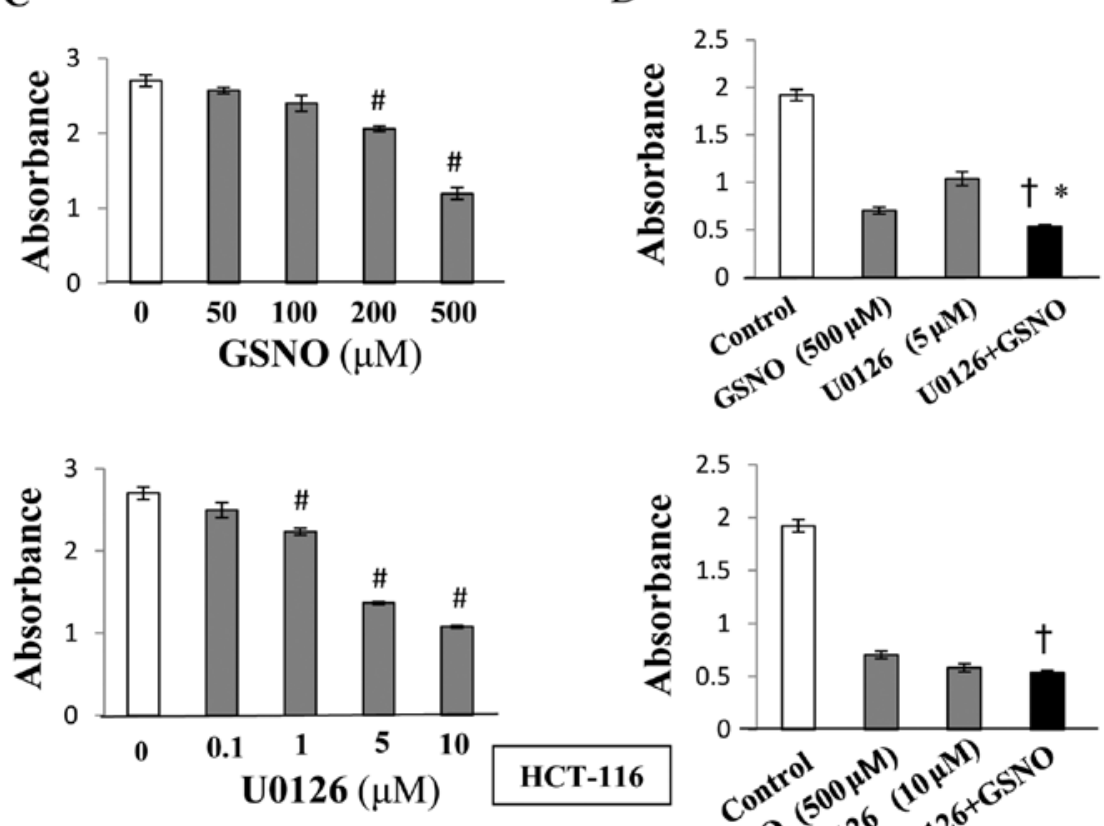

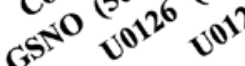
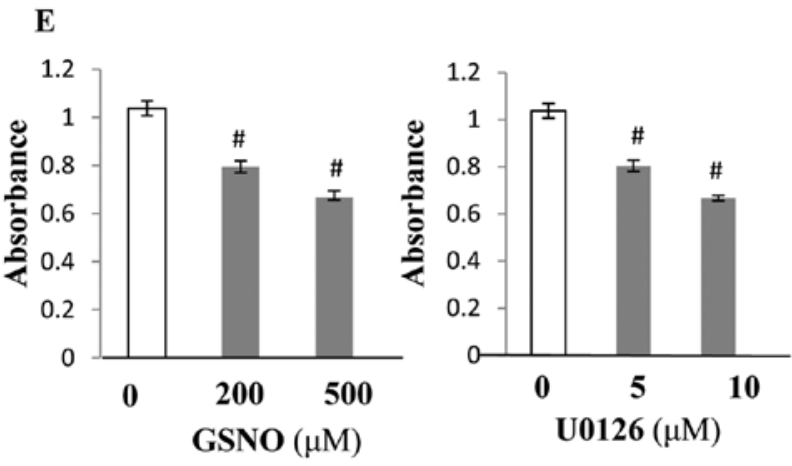

Panc-1

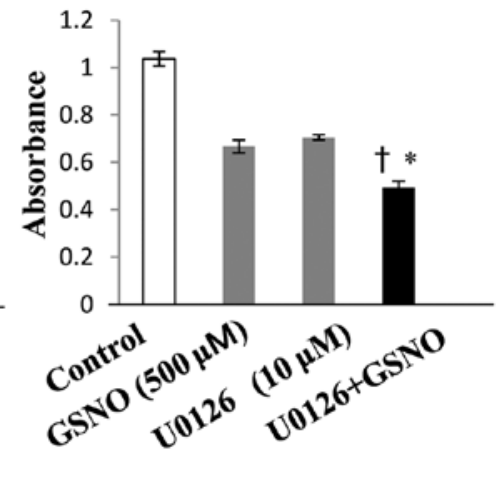

Figure 4. NO donor alone and MEK inhibitor alone significantly inhibit the proliferation of cancer cells in a dose-dependent manner, when the cells were incubated in medium containing with FBS. The combination of NO donor and MEK inhibitor inhibit the proliferation of MIAPaCa-2 cells compared to either NO donor or MEK inhibitor alone. 
$\mathbf{F}$
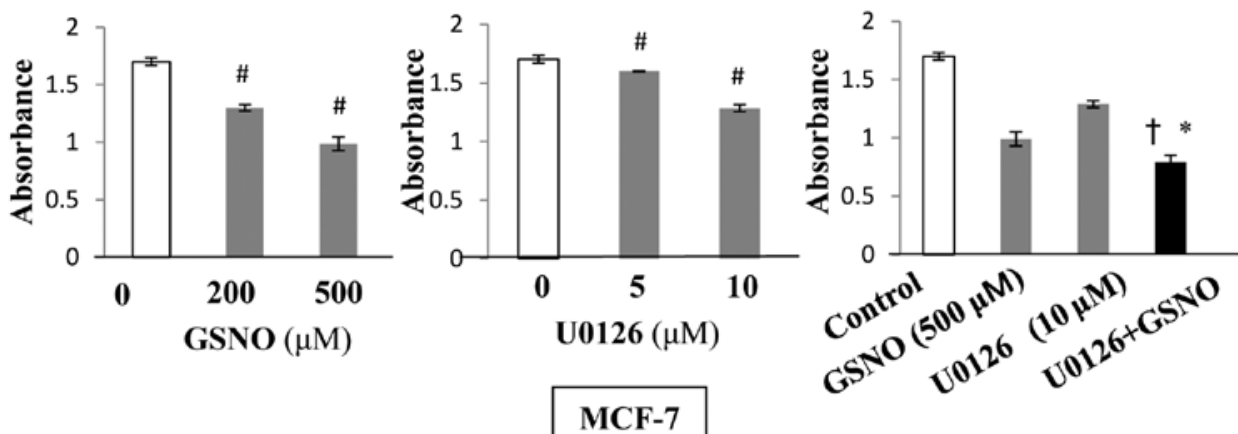

G
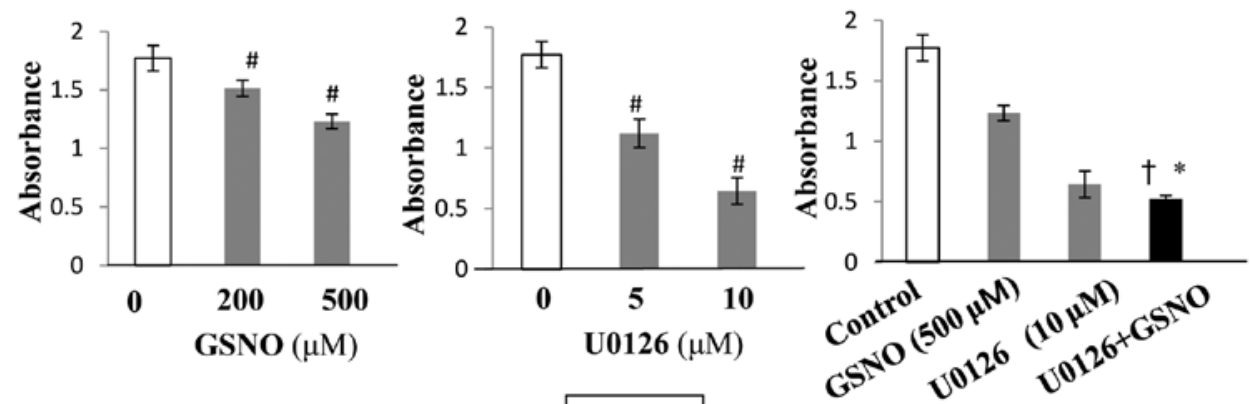

HT-29
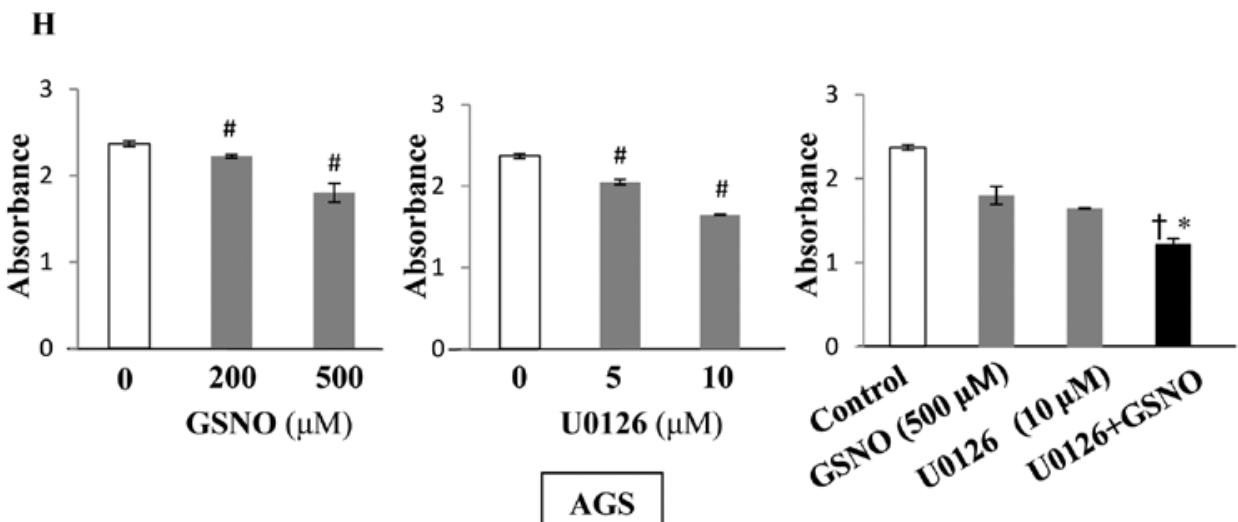

Figure 4. Continued. MIAPaCa-2, HCT-116, Panc-1, MCF-7, HT-29 and AGS cells were incubated with GSNO (0-500 $\mu$ M) alone or U0126 (0-10 $\mu$ M) alone in medium containing 10\% FBS for $72 \mathrm{~h}$. Cancer cells, were incubated with the combination of GSNO and U0126 in medium containing $10 \%$ FBS for $72 \mathrm{~h}$ and then cell proliferation was determined. (A and B) MIAPaCa-2 cells, (C and D) HCT-116 cells, (E) Panc-1 cells, (F) MCF-7 cells, (G) HT-29 cells, (H) AGS cells . ${ }^{\#} \mathrm{P}<0.05$, compared to control; ${ }^{\mathrm{T}} \mathrm{P}<0.05$, compared to GSNO alone; ${ }^{\mathrm{P}}<0.05$, compared to U0126 alone.

The combination of NO donor and MEK inhibitor inhibits the proliferation of cancer cell lines compared to either $N O$ donor or MEK inhibitor alone. IGF-IR protein was expressed in MIAPaCa-2, HCT-116, Panc-1, MCF-7, HT-29 and AGS cells, and EGFR protein was expressed in MIAPaCa-2, HCT-116, Panc-1, HT-29 and AGS cells (Fig. 3). To evaluate the effects of the combination of NO donor and MEK inhibitor on MIAPaCa-2, HCT-116, Panc-1, MCF-7, HT-29 and AGS cells, we analyzed cell proliferation using an MTT assay after the cells were treated with NO donor and MEK inhibitor for 72 h. As shown in Fig. 4A, GSNO alone and MEK inhibitor alone significantly inhibited the proliferation of MIAPaCa-2 cells in a dose-dependent manner when the cells were incubated with FBS. The combination of NO donor $(200 \mu \mathrm{M}$, $500 \mu \mathrm{M})$ and MEK inhibitor $(10 \mu \mathrm{M})$ decreased the prolif- eration of MIAPaCa-2 cells compared to either NO donor or MEK inhibitor alone when the cells were incubated with FBS (Fig. 4B). Similar results were found in HCT-116, Panc-1, MCF-7, HT-29 and AGS cells (Fig. 4C-H).

GSNO alone and MEK inhibitor alone significantly inhibited the proliferation of MIAPaCa-2 cells in a dosedependent manner when the cells were incubated with IGF-I (Fig. 5A and B). The combination of NO donor $(100 \mu \mathrm{M})$ and MEK inhibitor $(10 \mu \mathrm{M})$ decreased the proliferation of MIAPaCa-2 cells compared to either NO donor or MEK inhibitor alone when the cells were incubated with IGF-I (Fig. 5C).

GSNO alone and MEK inhibitor alone significantly inhibited the proliferation of HCT-116 cells in a dosedependent manner when the cells were incubated with EGF 

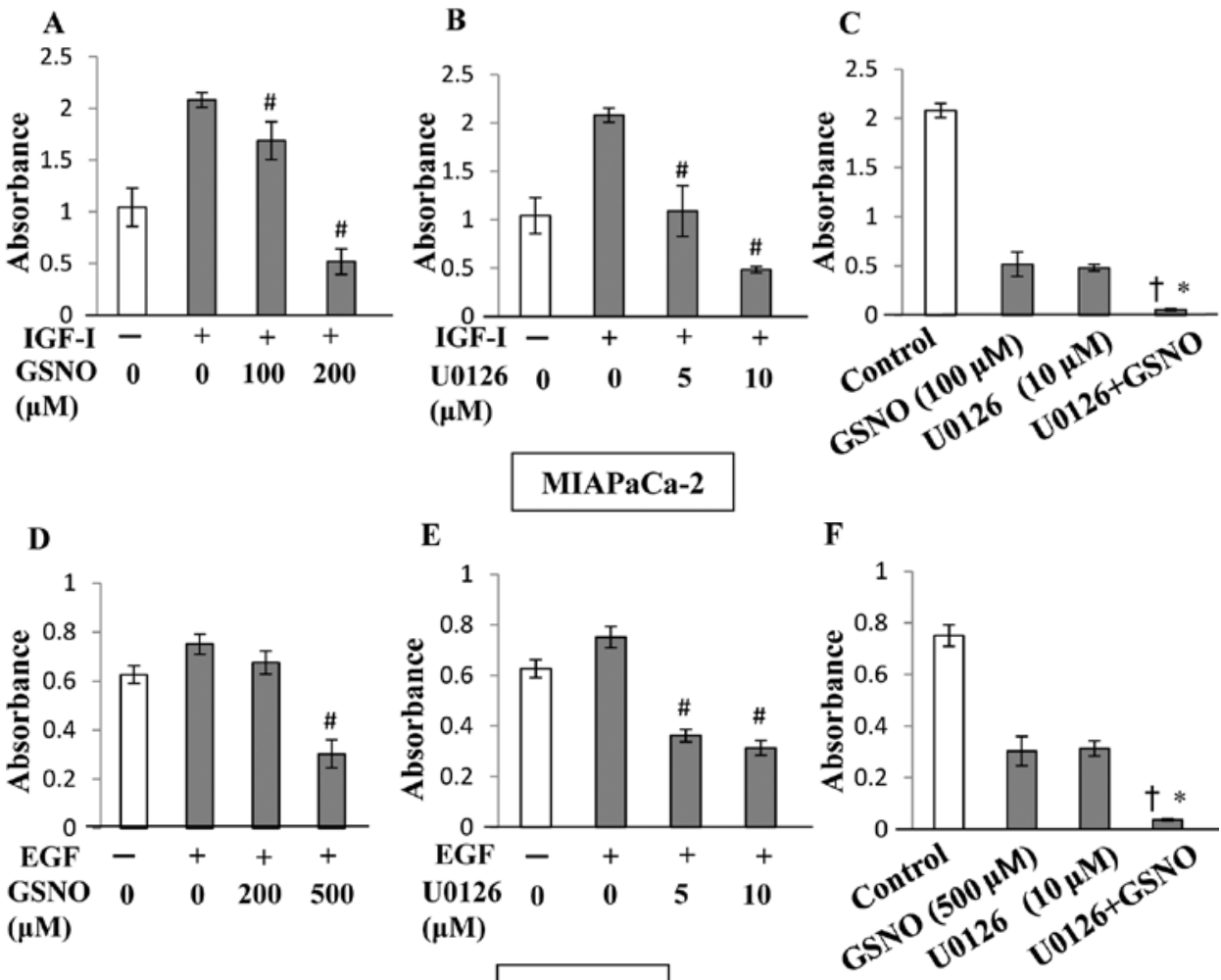

HCT-116

Figure 5. NO donor alone and MEK inhibitor alone significantly inhibit the proliferation of MIAPaCa-2 cells in a dose-dependent manner, when the cells were incubated with IGF-I (A and B). The combination of NO donor and MEK inhibitor inhibits the proliferation of MIAPaCa-2 cells compared to either NO donor or MEK inhibitor alone (C). MIAPaCa-2 cells were incubated with the combination of GSNO and U0126 in medium containing IGF-I (100 nM) for $72 \mathrm{~h}$ and then cell proliferation was determined. ${ }^{\prime \prime} \mathrm{P}<0.05$, compared to control; ${ }^{\mathrm{P}} \mathrm{P}<0.01$, compared to GSNO alone; ${ }^{*} \mathrm{P}<0.01$, compared to U0126 alone. NO donor alone and MEK inhibitor alone significantly inhibit the proliferation of HCT-116 cells in a dose-dependent manner, when the cells were incubated with EGF (D and E). The combination of NO donor and MEK inhibitor inhibits the proliferation of HCT-116 cells compared to either NO donor or MEK inhibitor alone (F). HCT-116 cells were incubated with the combination of GSNO and U0126 in medium containing EGF (100 ng/ml) for $72 \mathrm{~h}$ and then cell proliferation was determined. ${ }^{"} \mathrm{P}<0.05$, compared to control; ${ }^{\dagger} \mathrm{P}<0.01$, compared to GSNO alone; ${ }^{*} \mathrm{P}<0.01$, compared to U0126 alone.

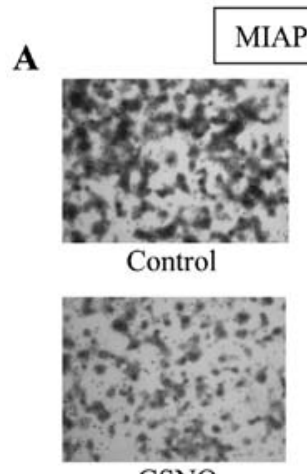

GSNO

B

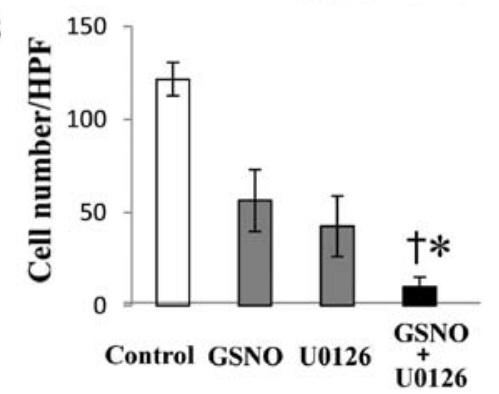

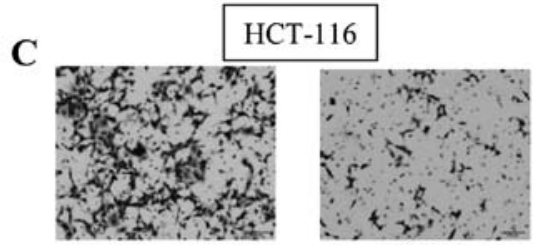

Control

U0126

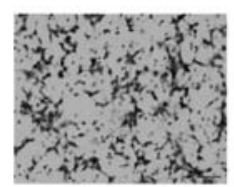

GSNO

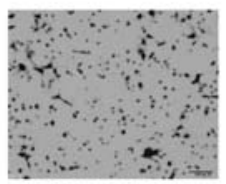

GSNO+U0126

D

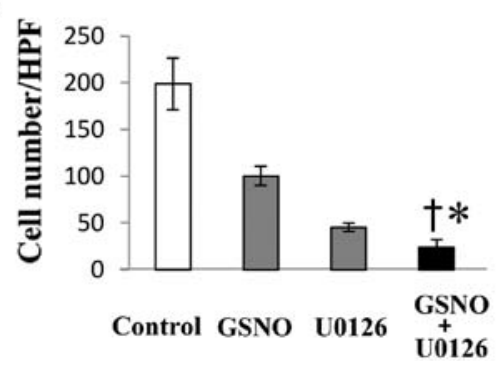

Figure 6. The combination of NO donor and MEK inhibitor inhibits the invasion of MIAPaCa-2 and HCT-116 cells compared to either NO donor or MEK inhibitor alone. Cell invasion was determined using BioCoat Matrigel invasion chambers. MIAPaCa-2 cells (A and B), or HCT-116 cells (C and D) were placed in the upper chambers. Conditioned medium from NIH $3 \mathrm{~T} 3$ cells was used as a chemoattractant. A and C show stained cancer cells, that migrated. Data shown are the results of triplicate experiments (B and D). Error bars indicate the standard errors of the means. ${ }^{\dagger} \mathrm{P}<0.01$, compared to GSNO alone; ${ }^{*} \mathrm{P}<0.01$, compared to U0126 alone. 
(Fig. 5D and E). The combination of NO donor $(500 \mu \mathrm{M})$ and MEK inhibitor $(10 \mu \mathrm{M})$ decreased the proliferation of HCT-116 cells compared to either NO donor or MEK inhibitor alone when the cells were incubated with EGF (Fig. 5F).

The combination of NO donor and MEK inhibitor decreases cancer cell invasion compared to either NO donor or MEK inhibitor alone. In the invasion assay, the addition of GSNO $(200 \mu \mathrm{M})$ alone and $\mathrm{U} 0126(10 \mu \mathrm{M})$ alone reduced the invasion of MIAPaCa-2 and HCT-116 cells. The combination of GSNO $(200 \mu \mathrm{M})$ and $\mathrm{U} 0126(10 \mu \mathrm{M})$ decreased the invasion of MIAPaCa-2 and HCT-116 compared to either GSNO $(200 \mu \mathrm{M})$ or U0126 (10 $\mu \mathrm{M})$ alone (Fig. 6A-D).

\section{Discussion}

In this study, we demonstrated that the combination of NO donor and MEK inhibitor inhibits both the PI3K/Akt and MEK/ERK pathways, and thus inhibits the proliferation and invasion of cancer cells. In contrast, GSNO alone upregulates MAPK pathway, although GSNO alone inhibits PI3K/Akt pathway. U0126 alone upregulates PI3K/Ak pathway, although U0126 inhibits MEK/ERK pathway. Fig. 7 illustrates our hypothesis on the molecular mechanism underlying the synergistic effect of the combination treatment with NO donor and MEK inhibitor in cancer cells.

IGF-I and EGF signaling play important roles in the proliferation and invasion of MIAPaCa- 2 and HCT-116 cells, consistent with previous reports $(1-3,24,25)$. IGF-IR and EGFR are expressed in various cancer cells, as we showed in this study. The MEK/ERK and PI3K/Akt pathways are two major pathways of IGF-I and EGF. Recent studies in vitro and in vivo suggest that antitumor therapy for K-Ras-mutant tumors requires dual inhibition of the MEK and PI3K pathways to achieve inhibition of tumor growth (26-28). The treatment that we propose is the dual inhibition of MAPK and PI3K pathways. NO inhibits IGF-IR and EGFR activity, as reported previously $(29,30)$. Furthermore, NO induces the degradation of IRS-1 protein and the phosphorylation of IRS-1 (14,29,30). In addition, Yasukawa et al reported that NO directly modifies Akt protein and inhibits its activity (11). Recent studies have shown that NO inhibits cell proliferation and induces apoptosis in various cells including cancer cells, in vitro and in vivo (14-21).

Ras regulates multiple intracellular signaling pathways, of which the best understood is the Ras-RAF-MEK-ERK pathway. Substantial efforts made over the years to target the activated Ras protein have been unsuccessful and the downstream kinases in the Ras cascade remain attractive as therapeutic targets (31). Consequently, intensive preclinical and clinical research has led to the development of small molecule kinase inhibitors of its downstream effector MEK. In most pancreatic cancers, and in approximately 35 to $40 \%$ of colorectal cancer, K-Ras is activated due to mutations $(32,33)$. $\mathrm{K}$-Ras mutations in MIAPaCa-2 and HCT-116 cells, have been reported previously $(34,35)$. Specific MEK1/2 inhibitors can inhibit the expression of phospho-ERK1/2 for various lengths of time in vitro (36-38). CI-1040, a MEK1/2 inhibitor, reduced tumor growth by $31.3 \%$ in mice inoculated with papillary thyroid carcinoma (PTC) cells carrying a BRAF mutation and by $47.5 \%$ in mice inoculated with PTC cells bearing a RET/

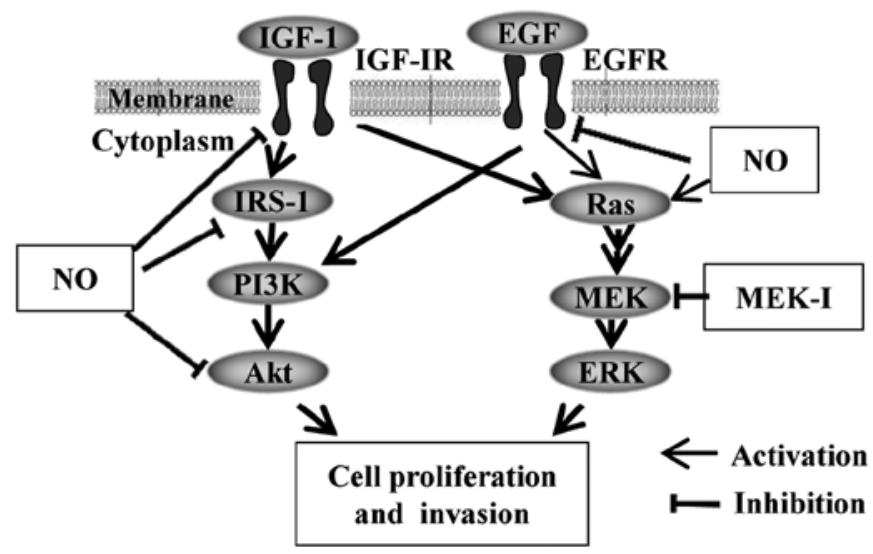

Figure 7. Schematic representation of our hypothesis on the molecular mechanism. The combination treatment of NO donor and MEK inhibitor downregulates PI3-K and MAPK pathways in cancer cells.

PTC1 rearrangement (39). Cl-1040 has been tested in other cancers, including colon cancer, breast cancer, non-small cell lung cancer (NSCLC), and melanoma, and was well tolerated by patients in phase I-II trials $(40,41)$. NO donor upregulates phosphorylation of ERK1/2, although NO donor downregulates the PI3K/Akt pathway. In the present study, we showed that the phosphorylation of ERK1/2 is upregulated by NO donor without the stimulating of growth factors in MIAPaCa-2 and HCT-116 cells. These results are in accordance with previous studies reporting that NO directly modifies $\mathrm{H}$-Ras and N-Ras through S-nitrosylation, resulting in the activation of their signaling $(22,42)$. The present study showed that U0126 completely inhibits phosphorylation of ERK1/2, although U0126 upregulates IGF-I- and EGF-stimulated Akt phosphorylation (Figs. 1 and 2). These results are in accordance with previous reports $(43,44)$. Furthermore, we showed that U0126 upregulates IGF-Iand EGF-stimulated phosphorylation of IGF-IR and EGFR. The U0126-induced upregulation of Akt phosphorylation may be explained by the upregulated phosphorylation of IGF-IR and EGFR. We surmise that a negative feedback mechanism from the inhibition of ERK activity may regulate this phenomenon. As described above, NO inhibits U0126-induced upregulated IGF-IR, EGFR, and Akt phosphorylation. These results suggest that the combination of NO donor and MEK inhibitor may be more effective in cancer therapy.

The usefulness of cancer therapy using NO, including inducible NO synthase gene therapy and administration of NO donor, was recently confirmed in animal models (45-47). Consequently, NO therapy has received considerable attention and is currently undergoing clinical evaluation for cancer prevention (48). On the other hand, MEK inhibitor is also feasible for cancer therapy $(40,41)$. We believe that combined treatment of NO donor and MEK inhibitor may be an effective and promising strategy for cancer treatment.

\section{Acknowledgements}

This study was supported by Grant-in-Aid for Scientific Research (grant nos. 18591517 and 20591633) from the Japanese Society for the Promotion of Science. 


\section{References}

1. Bergmann U, Funatomi H, Yokoyama M, Beger HG and Korc M: Insulin-like growth factor I overexpression in human pancreatic cancer: evidence for autocrine and paracrine roles. Cancer Res 55: 2007-2011, 1995

2. Furukawa M, Raffeld M, Mateo C, et al: Increased expression of insulin-like growth factor I and/or its receptor in gastrinomas is associated with low curability, increased growth, and development of metastases. Clin Cancer Res 11: 3233-3242, 2005.

3. Kim HJ, Litzenburger BC, Cui X, et al: Constitutively active type I insulin-like growth factor receptor causes transformation and xenograft growth of immortalized mammary epithelial cells and is accompanied by an epithelial-to-mesenchymal transition mediated by NF-kappaB and snail. Mol Cell Biol 27: 3165-3175, 2007.

4. Salomon DS, Brandt R, Ciardiello F and Normanno N: Epidermal growth factor-related peptides and their receptors in human malignancies. Crit Rev Oncol Hematol 19: 183-232, 1995.

5. Normanno N, Bianco C, De Luca A, Maiello MR and Salomon DS: Target-based agents against ErbB receptors and their ligands: a novel approach to cancer treatment. Endocr Relat Cancer 10: 1-21, 2003.

6. Ito T, Sasaki Y and Wands JR: Overexpression of human insulin receptor substrate 1 induces cellular transformation with activation of mitogen-activated protein kinases. Mol Cell Biol 16: 943-951, 1996 .

7. Tanaka S and Wands JR: A carboxy-terminal truncated insulin receptor substrate-1 dominant negative protein reverses the human hepatocellular carcinoma malignant phenotype. J Clin Invest 98: 2100-2108, 1996.

8. Park HS, Huh SH, Kim MS, Lee SH and Choi EJ: Nitric oxide negatively regulates c-Jun $\mathrm{N}$-terminal kinase/stress-activated protein kinase by means of S-nitrosylation. Proc Natl Acad Sci USA 97: 14382-14387, 2000.

9. Reynaert NL, Ckless K, Korn SH, et al: Nitric oxide represses inhibitory kappaB kinase through S-nitrosylation. Proc Natl Acad Sci USA 101: 8945-8950, 2004.

10. Mannick JB, Hausladen A, Liu L, et al: Fas-induced caspase denitrosylation. Science 284: 651-654, 1999.

11. Yasukawa T, Tokunaga E, Ota H, Sugita H, Martyn JA and Kaneki M: S-nitrosylation-dependent inactivation of Akt/protein kinase B in insulin resistance. J Biol Chem 280: 7511-7518, 2005.

12. Ambs S, Merriam WG, Ogunfusika MO, et al: p53 and vascular endothelial growth factor regulate tumor growth of NOS2expressing human carcinoma cells. Nat Med 4: 1371-1376, 1998.

13. Camp ER, Yang A, Liu W, et al: Roles of nitric oxide synthase inhibition and vascular endothelial growth factor receptor-2 inhibition on vascular morphology and function in an in vivo model of pancreatic cancer. Clin Cancer Res 12: 2628-2633, 2006.

14. Sugita H, Kaneki M, Furuhashi S, Hirota M, Takamori H and $\mathrm{Baba} \mathrm{H}$ : Nitric oxide inhibits the proliferation and invasion of pancreatic cancer cells through degradation of insulin receptor substrate-1 protein. Mol Cancer Res 8: 1152-1163, 2010.

15. Kalivendi SV, Kotamraju S, Zhao H, Joseph J and Kalyanaraman B: Doxorubicin-induced apoptosis is associated with increased transcription of endothelial nitric-oxide synthase. Effect of antiapoptotic antioxidants and calcium. J Biol Chem 276: 47266-47276, 2001.

16. Wang B, Wei D, Crum VE, et al: A novel model system for studying the double-edged roles of nitric oxide production in pancreatic cancer growth and metastasis. Oncogene 22 1771-1782, 2003.

17. Peshes-Yaloz N, Rosen D, Sondel PM, Krammer PH and Berke G: Up-regulation of Fas (CD95) expression in tumour cells in vivo. Immunology 120: 502-511, 2007.

18. Kotamraju S, Williams CL and Kalyanaraman B: Statin-induced breast cancer cell death: role of inducible nitric oxide and arginase-dependent pathways. Cancer Res 67: 7386-7394, 2007.

19. Notas G, Nifli AP, Kampa M, Vercauteren J, Kouroumalis E and Castanas E: Resveratrol exerts its antiproliferative effect on HepG2 hepatocellular carcinoma cells, by inducing cell cycle arrest, and NOS activation. Biochim Biophys Acta 1760 1657-1666, 2006.

20. Jarry A, Charrier L, Bou-Hanna C, et al: Position in cell cycle controls the sensitivity of colon cancer cells to nitric oxidedependent programmed cell death. Cancer Res 64: 4227-4234, 2004.
21. Chawla-Sarkar M, Bauer JA, Lupica JA, et al: Suppression of NF-kappa B survival signaling by nitrosylcobalamin sensitizes neoplasms to the anti-tumor effects of Apo2L/TRAIL. J Biol Chem 278: 39461-39469, 2003.

22. Lim KH, Ancrile BB, Kashatus DF and Counter CM: Tumour maintenance is mediated by eNOS. Nature 452: 646-649, 2008.

23. Shields JM, Pruitt K, McFall A, Shaub A and Der CJ: Understanding Ras: 'it ain't over 'til it's over'. Trends Cell Biol 10: $147-154,2000$

24. Van der Heyden MA, van Bergen en Henegouwen PM, De Ruiter N, et al: The actin binding domain of the epidermal growth factor receptor is required for EGF-stimulated tissue invasion. Exp Cell Res 234: 521-526, 1997.

25. Baselga $\mathbf{J}$ and Arteaga CL: Critical update and emerging trends in epidermal growth factor receptor targeting in cancer. J Clin Oncol 23: 2445-2459, 2005.

26. Engelman JA, Chen L, Tan X, et al: Effective use of PI3K and MEK inhibitors to treat mutant Kras G12D and PIK3CA H1047R murine lung cancers. Nat Med 14: 1351-1356, 2008.

27. Wee S, Jagani Z, Xiang KX, et al: PI3K pathway activation mediates resistance to MEK inhibitors in KRAS mutant cancers. Cancer Res 69: 4286-4293, 2009.

28. Yu K, Toral-Barza L, Shi C, Zhang WG and Zask A: Response and determinants of cancer cell susceptibility to PI3K inhibitors: combined targeting of PI3K and Mek1 as an effective anticancer strategy. Cancer Biol Ther 7: 307-315, 2008.

29. Murillo-Carretero M, Torroglosa A, Castro C, Villalobo A and Estrada C: S-Nitrosylation of the epidermal growth factor receptor: a regulatory mechanism of receptor tyrosine kinase activity. Free Radic Biol Med 46: 471-479, 2009.

30. Studer RK: Nitric oxide decreases IGF-1 receptor function in vitro; glutathione depletion enhances this effect in vivo. Osteoarthritis Cartilage 12: 863-869, 2004.

31. Sebolt-Leopold JS: Advances in the development of cancer therapeutics directed against the RAS-mitogen-activated protein kinase pathway. Clin Cancer Res 14: 3651-3656, 2008.

32. Almoguera C, Shibata D, Forrester K, Martin J, Arnheim N and Perucho M: Most human carcinomas of the exocrine pancreas contain mutant c-K-ras genes. Cell 53: 549-554, 1988.

33. Bos JL, Fearon ER, Hamilton SR, et al: Prevalence of ras gene mutations in human colorectal cancers. Nature 327: 293-297, 1987.

34. Bocci G, Fioravanti A, Orlandi P, et al: Fluvastatin synergistically enhances the antiproliferative effect of gemcitabine in human pancreatic cancer MIAPaCa-2 cells. Br J Cancer 93: 319-330, 2005.

35. Allgayer H, Wang H, Shirasawa S, Sasazuki T and Boyd D: Targeted disruption of the K-ras oncogene in an invasive colon cancer cell line down-regulates urokinase receptor expression and plasminogen-dependent proteolysis. $\mathrm{Br} \mathbf{J}$ Cancer 80: 1884-1891, 1999.

36. Favata MF, Horiuchi KY, Manos EJ, et al: Identification of a novel inhibitor of mitogen-activated protein kinase kinase. J Biol Chem 273: 18623-18632, 1998.

37. Liu D, Liu Z, Jiang D, Dackiw AP and Xing M: Inhibitory effects of the mitogen-activated protein kinase kinase inhibitor CI-1040 on the proliferation and tumor growth of thyroid cancer cells with BRAF or RAS mutations. J Clin Endocrinol Metab 92: 4686-4695, 2007.

38. Henderson YC, Fredrick MJ and Clayman GL: Differential responses of human papillary thyroid cancer cell lines carrying the RET/PTC1 rearrangement or a BRAF mutation to MEK 1/2 inhibitors. Arch Otolaryngol Head Neck Surg 133: 810-815, 2007.

39. Henderson YC, Ahn SH and Clayman GL: Inhibition of the growth of papillary thyroid carcinoma cells by CI-1040. Arch Otolaryngol Head Neck Surg 135: 347-354, 2009.

40. Haura EB, Ricart AD, Larson TG, et al: A phase II study of PD-0325901, an oral MEK inhibitor, in previously treated patients with advanced non-small cell lung cancer. Clin Cancer Res 16: 2450-2457, 2010.

41. LoRusso PM, Krishnamurthi SS, Rinehart JJ, et al: Phase I pharmacokinetic and pharmacodynamic study of the oral MAPK/ ERK kinase inhibitor PD-0325901 in patients with advanced cancers. Clin Cancer Res 16: 1924-1937, 2010.

42. Ibiza S, Perez-Rodriguez A, Ortega A, et al: Endothelial nitric oxide synthase regulates N-Ras activation on the Golgi complex of antigen-stimulated T cells. Proc Natl Acad Sci USA 105: 10507-10512, 2008. 
43. Yu CF, Liu ZX and Cantley LG: ERK negatively regulates the epidermal growth factor-mediated interaction of Gab1 and the phosphatidylinositol 3-kinase. J Biol Chem 277: 19382-19388, 2002.

44. Yoon YK, Kim HP, Han SW, et al: Combination of EGFR and MEK1/2 inhibitor shows synergistic effects by suppressing EGFR/HER3-dependent AKT activation in human gastric cancer cells. Mol Cancer Ther 8: 2526-2536, 2009.

45. Adams C, McCarthy HO, Coulter JA, et al: Nitric oxide synthase gene therapy enhances the toxicity of cisplatin in cancer cells. J Gene Med 11: 160-168, 2009.

46. Kiziltepe T,Hideshima T,Ishitsuka K, et al: JS-K, a GST-activated nitric oxide generator, induces DNA double-strand breaks, activates DNA damage response pathways, and induces apoptosis in vitro and in vivo in human multiple myeloma cells. Blood 110 709-718, 2007
47. Wang Z, Cook T, Alber S, et al: Adenoviral gene transfer of the human inducible nitric oxide synthase gene enhances the radiation response of human colorectal cancer associated with alterations in tumor vascularity. Cancer Res 64: 1386-1395, 2004.

48. Ma Q, Wang Y, Gao X, Ma Z and Song Z: L-arginine reduces cell proliferation and ornithine decarboxylase activity in patients with colorectal adenoma and adenocarcinoma. Clin Cancer Res 13: 7407-7412, 2007. 